\title{
BMJ Open Women and substance use: a qualitative study on sexual and reproductive health of women who use drugs in Delhi, India
}

\author{
Vartika Sharma, ${ }^{1}$ Avina Sarna, ${ }^{2}$ Waimar Tun, ${ }^{3}$ Lopamudra Ray Saraswati, ${ }^{2}$ \\ Ibou Thior, ${ }^{4}$ Ira Madan, ${ }^{5}$ Stanley Luchters ${ }^{1,6,7}$
}

To cite: Sharma V, Sarna A, Tun W, et al. Women and substance use: a qualitative study on sexual and reproductive health of women who use drugs in Delhi, India. BMJ Open 2017;7:e018530. doi:10.1136/ bmjopen-2017-018530

- Prepublication history for this paper is available online. To view these files, please visit the journal online (http://dx.doi. org/10.1136/bmjopen-2017018530).

Received 5 July 2017

Revised 13 September 2017

Accepted 27 September 2017

CrossMark

${ }^{1}$ International Centre for Reproductive Health, Ghent University, Belgium (former Population Council), Ghent, Oost-Vlaanderen, Belgium ${ }^{2}$ Population Council, New Delhi, India

${ }^{3}$ Population Council, Washington, DC, USA

${ }^{4}$ PATH, Washington, DC, USA

${ }^{5}$ Sahara Centre for Residential Care and Rehabilitation, New Delhi, India

${ }^{6}$ Burnet Institute, Melbourne, Victoria, Australia

${ }^{7}$ School of Public Health and Preventive Medicine, Monash University, Melbourne, Victoria, Australia

Correspondence to

Vartika Sharma;

vs.vartikas@gmail.com

\section{ABSTRACT}

Objectives To explore contextual factors that increase vulnerabilities to negative sexual and reproductive health (SRH) outcomes and possible differences in SRH-related behaviours and the needs of women who use drugs (WUD) through non-injecting and injecting routes.

Design Qualitative study design using semi-structured in-depth interviews.

Participants Twenty women who injected drugs in the past 3 months and 28 women who reported using drugs through non-injecting routes in the past 1 month.

Setting Interviews were conducted at community-based, drop-in centres in Delhi, India.

Results Study findings illustrate that WUD were sexually active and had multiple sex partners including clients of sex work. Transient relationships were reported and many participants engaged in unsafe sex. Factors which affected safe sex behaviours included: gender power imbalance, limited agency for decision-making, lack of accurate information for correct self-risk assessment, and being under the influence of drugs. Despite high awareness, low and inconsistent contraceptive use was reported. Some participants were coerced to conceive while a few others reported their inability to conceive. Violence was a key determinant for SRH outcomes. Perception of certain adverse health outcomes (such as infertility) to be 'common and expected among WUD' influenced access to healthcare. Further, healthcare providers' stigmatising attitudes and lack of women-centric services deterred women from uptake of healthcare services.

Conclusion Findings highlight that SRH-related behaviours and needs of this group are a complex interplay of multiple determinants which need to be addressed at all levels: individual, family, community and institutional. It is imperative to roll out a 'one-stopshop' for a comprehensive package of health services. Expansion of existing drop-in-centres could be considered for setting-up community-based women-centric services with appropriate linkage to drug dependence treatment and reproductive health services.

\section{INTRODUCTION}

Women who use drugs (WUD) are notoriously hard to reach and they maintain a relatively subordinate position to men in the drug-using subculture. Drug use is often seen to be contrary to the socially normative

\section{Strengths and limitations of this study}

- Qualitative study design allowed for a more detailed and nuanced contextual understanding of the health needs and behavioural choices of women who use drugs.

- Semi-structured in-depth interviews were found to be appropriate to discuss intimate and sensitive issues such as sex work, multiple sex partners, and intimate partner violence.

- Collaborating with an experienced, local NGO was instrumental in ensuring appropriateness of the study protocol and data collection tools for the target population which resulted in participants' trust in the study purpose.

- Considering the study was conducted with a small sample of women in a defined geographical area of Delhi, it may not be representative of such women in other urban areas or even other parts of Delhi.

roles of women as mothers, partners and caretakers, leaving WUD to face greater stigma and risks and to experience a range of specific harms at higher levels than men who use drugs. ${ }^{1}$ India has a large population of people who inject drugs (PWID), estimated at $177000 .^{2}$ The number of women who inject drugs (women/I) is estimated to be in the range of 10055-33392. ${ }^{3}$ However, national level estimates for women who use drugs through non-injecting routes (women/ NI) are not available.

Globally, significant gender-related differences have been observed between male and female drug users. A study in London reported that women used smaller amounts of drugs, for a shorter duration, and were less likely to inject than their male counterparts, thereby suggesting variance in their vulnerabilities to engage in potentially risky behaviours. Furthermore, drug-using sex partners were found to have an important influence on women's drug use behaviours. ${ }^{4}$ A study with 176 WUD in Bangladesh reported that less than half of the women started with injecting, as most transitioned from smoking to injecting 
behaviours. ${ }^{5}$ Irrespective of the route of administration, many drugs increase sexual pleasure which may result in increased unsafe sexual activity. ${ }^{6-8}$ Poor socioeconomic conditions create an urgency that contributes to unprotected sex with clients and associated risk for HIV and other sexually transmitted infections (STIs). A study with women/I in northeast India showed that $40 \%$ of participants engaged in occasional sex work while one-fourth engaged in professional sex work. ${ }^{9}$ Other studies have also reported that WUD resort to sex work to obtain drugs from their sex partners or to earn money for purchasing drugs. ${ }^{10-12}$ Lucas $e t \mathrm{al}^{13}$ in their study with 14821 PWID across 15 cities in India reported a threefold higher HIV prevalence among women compared with men; however, women/I were almost exclusively recruited from the north-eastern states of the country. ${ }^{13}$

While injection drug use is strongly associated with HIV, a number of studies have also found high HIV prevalence among predominantly heterosexual, non-injecting drug users ranging from $13 \%$ in Canada to $29 \%$ in Russia and $43 \%$ in China ${ }^{14}$; these prevalence rates are significantly higher than the prevalence among women in the general population of these countries.

Studies in India have reported inadequate uptake of HIV prevention and care services as they are not found to be gender responsive. ${ }^{15}$ Further, these services do not cater to women/NI unless they identify themselves as sex workers or transition onto injection drug use, which often is in the later stage of the drug use trajectory. ${ }^{15} 16$

Much of the evidence around WUD in India is limited to the north-eastern states of Manipur and Nagaland, since they consistently report high HIV prevalence fuelled by injection drug use. ${ }^{15}$ However, these states are ethnically and culturally distinct, geographically isolated from rest of the country, and characterised by long-standing civil insurgent movements, deeply-felt social conservatism, and substantial underdevelopment ${ }^{15}$; hence, generalisation of the study's findings to other parts of India is severely limited. During the mid-term appraisal of the National AIDS Control Program Phase IV (2016), the state of Delhi showed emerging concerns about PWID. ${ }^{17}$

Considering the state is a relatively recent entry in the drug using scene in India and women in Delhi constitute a much smaller proportion of the drug using population, ${ }^{18}$ their sexual and reproductive health (SRH)-related vulnerabilities (beyond HIV) and social factors have not been researched and understood. This qualitative study thus explores contextual factors that increase their vulnerabilities to negative SRH-related outcomes and aims to understand possible differences in the behaviours and needs of WUD through injecting and non-injecting routes.

\section{METHODS}

An interpretivist approach, using the social constructivist theory ${ }^{19}$ was used to understand how certain negative SRH-related outcomes are embedded with cultural meaning, and are socially constructed at an experiential level, based on how individuals come to understand and live with their negative health conditions.

\section{Research team}

Seven researchers (five women, two men) participated in the study. VS, AS, WT, LS and IM had experience of working with people who use drugs in India but had no prior relationship with any of the participants. SL had extensively worked on SRH-related issues among women in resource-constraint settings, while IT had been involved in designing research studies for most-at-risk groups for HIV.

\section{Settings and participants}

A prospective cohort study (May 2011 to April 2014) was conducted in Delhi to assess HIV sero-incidence among PWID and receive comprehensive HIV prevention services. ${ }^{18}{ }^{20}$ Participants were over 18 years of age and had injected drugs at least once in the last 3 months. ${ }^{20}$ They were recruited through peer referral, targeted outreach in hotspots and as walk-in clients for HIV prevention services provided through five drop-in-centres (DIC) which also served as data collection centres. This study was approved by the Population Council Institutional Review Board (USA), PATH, Research Ethics Committee (USA), and Technical Resource Group and Ethics Committee of National AIDS Control Organisation (India).

A qualitative study design was used for conducting in-depth interviews with participants recruited through purposive sampling. Women/I enrolled in the HIV sero-incidence study were invited to participate in this qualitative study. To complement the parent cohort study, women/NI were recruited. Women/NI, who were above 18 years of age, and had used drugs through non-injecting routes-such as ingesting, inhaling, chasing, snorting, sniffing or smoking - at least once in the last 1 month, were recruited through targeted outreach at hotspots linked to the five DICs. Recruitment of new participants was discontinued once data saturation was achieved. Interviews were conducted between August 2012 and September 2013. Women/I received a lower compensation (US\$1.50) compared with women/NI (US\$2.20) since their visit to the DIC was part of their participation in the HIV sero-incidence study and hence they received compensation only for time required for the interview. However, the latter visited the DIC specifically for participating in this study and thus received additional compensation for their travel time.

Written informed consent obtained from the participants apprised them of the study objectives and procedures. For illiterate participants, informed consent was read out and a thumb imprint was taken in the presence of a witness. Participants have been given fictitious names in this paper to ensure confidentiality. 


\section{Data collection}

The interview guide was pilot-tested for clarity in the local language (Hindi), comprehension, content and cultural sensitivity. Mock interviews were conducted with female outreach workers (ORWs), who were mostly former drug users and thus familiar with the context of the study population. A trained female interviewer with prior experience of working with this population conducted face-toface interviews in an area with auditory and visual privacy at the DICs. All interviews were completed in one sitting and lasted approximately 35-40 min.

Interviews were audiorecorded, transcribed and translated into English for analysis. Participant debriefing was not done to avoid participation overburden. Atlas Ti software $(\mathrm{GmbH}$, Berlin; version 6.2) was used for coding and data analysis.

\section{Data analysis}

A qualitative descriptive approach, guided by Braun and Clarke, ${ }^{21}$ was used for data analysis. ${ }^{21}$ During data collection, interview transcripts and field notes were reviewed and analysed. This interim analysis helped monitor data saturation, and pursue emerging avenues of inquiry in further depth. ${ }^{22}$

Two researchers read the transcripts independently for data immersion and inductively developed a coding scheme and then compared them to prepare a final code list. Approximately $10 \%$ of the interviews were doublecoded to discuss the degree of agreement in coding; team discussions were used to resolve any disagreements and reach a consensus. Codes were analysed and sorted to identify over-arching themes and sub-themes. Data reduction, based on the research question and study objectives, occurred throughout the analysis.

Key themes and sub-themes that were identified include: unsafe sex characterised by the nature of relationship-regular and paid sexual partnerships (power imbalance, intimate partner violence (IPV) and stigma); negative SRH-related outcomes (symptoms suggestive of a reproductive tract infection (RTI)/STI; coerced or unfulfilled desire for conception, unmet family planning needs) coupled with low uptake of healthcare services.

\section{RESULTS}

We interviewed 20 women/I and 28 women/NI. table 1 provides an overview of their sociodemographic profile. The median age of women/I and women/NI was 35 years and 29.5 years, respectively. Most participants were illiterate, over half lived in the streets (ie, they were homeless), and most were self-employed in various informal daily wage activities, some of which were illegal. Almost one-third of the participants reported multiple marriages and most had children. A higher proportion of women/ NI were presently engaged in sex work.
Table 1 Sociodemographic profile

\begin{tabular}{|c|c|c|}
\hline $\begin{array}{l}\text { Sociodemographic } \\
\text { characteristics }\end{array}$ & Women/I $(n=20)$ & Women/NI ( $\mathrm{n}=\mathbf{2 8})$ \\
\hline $\begin{array}{l}\text { Age (median, IQR) in } \\
\text { years }\end{array}$ & $35(25-40)$ & $29.5(22-35)$ \\
\hline \multicolumn{3}{|l|}{ Education } \\
\hline Illiterate & 17 & 19 \\
\hline Class I-XII & 3 & 6 \\
\hline Graduate and above & 0 & 0 \\
\hline No formal schooling & 0 & 3 \\
\hline \multicolumn{3}{|l|}{ Accommodation } \\
\hline Street-based & 10 & 15 \\
\hline Home-based & 10 & 13 \\
\hline \multicolumn{3}{|l|}{ Employment status* } \\
\hline Unemployed & 5 & 3 \\
\hline Daily wage work & 8 & 5 \\
\hline Sex work & 4 & 11 \\
\hline Drug peddling & 1 & 7 \\
\hline Pick-pocketing & 3 & 2 \\
\hline Begging & 3 & 11 \\
\hline \multicolumn{3}{|l|}{ Marital status } \\
\hline Married & 11 & 12 \\
\hline Separated/divorced & 6 & 9 \\
\hline Widow & 3 & 4 \\
\hline Single & 0 & 3 \\
\hline \multicolumn{3}{|c|}{ Number of children ever bornt } \\
\hline None & 4 & 2 \\
\hline $1-2$ & 8 & 10 \\
\hline$>2$ & 8 & 13 \\
\hline
\end{tabular}

*Some women reported more than one job.

tOnly women who reported they had ever been married were asked about the number of children ever born, since childbearing without marriage is a social taboo in India. Women/l, women who inject drugs; women/NI, women who use drugs through non-injecting routes.

\section{UNSAFE SEX, CHARACTERISED BY THE NATURE OF THE RELATIONSHIP}

Regular partners: sex partners and drug use companions

Regular partners had a crucial role in the drug use practices and trajectory of the study participants, as many women were introduced to drugs by these men, mainly to avoid confrontation and requests for them to discontinue using drugs. Once addicted, participants reported that they served as a useful resource to arrange drugs for themselves as well as their partners. Thus, most women and their regular partners shared a dual relationship of sexual and drug using partnerships.

However, many participants reported a series of regular partners and the reasons for unsteady relationships were largely related to the fact that their regular 
partners had multiple sex partners-women from their previous marriage, other live-in-partners, casual sex partners or sex workers. A few women/I reported being abandoned by their husbands who went on to marry other women, though no legal formalities of divorce proceedings were cited. In other instances, women themselves discontinued the relationship because of their partner's infidelity.

My husband left me when my second child was born... He said that the other women loved him more. So, I left everything and came here (Delhi)...

\section{Zubina, 40-year-old woman/I}

He was wrong and he used to do wrong things (sex) with outside women also... he was a flirt.

\section{Farha, 34-year-old woman/NI}

Participants who made efforts to stop their partners from having sex outside of marriage ended up experiencing verbal and physical violence. Some women reported self-inflicting harm on themselves due to circumstances which they could no longer bear or due to their requests and feelings being unheard.

He used to hit me many times... (showing her hand) ...I slit my wrist with a blade after drinking alcohol...I was fighting with him that when he has everything, why does he go after other women... He was drunk so he slapped me and I could do nothing... so in anger I slashed my wrist.

\section{Raano, 35-year-old woman/NI}

Marital conflicts related to drug use, inability to provide appropriate child care and violence were other reasons cited which pushed women out of marriage. Some women also reported their partner's long incarceration period or death as reasons to move on to other relationships. To survive on the street or to support their families, women reported the need for a man's protection and in turn looked for a new partner. Interaction with other men who lived on the street and male members of the drug using network provided opportunities for such new partnerships to form.

\section{Unsafe sex within regular partnerships}

Many women were sexually active with regular partners and reported being cognisant of the risk of infection transmission and unplanned pregnancies through unprotected sex, and condoms being an effective way of preventing it; however, condom use was infrequently reported.

Fear of breach of trust and lack of enjoyment by both partners deterred condom use. Further, perception of 'sex being safe' within the institution of marriage was an important reason for infrequent condom use, except for a few participants who were aware that their partners had sex outside of marriage.
When it is your husband it (sex) is not that risky so it is mostly done without condom... And it is fine because sometimes there is no condom and your man is in a mood (to have sex).

\section{Chanda, 32-year-old woman/NI}

I explained to him (husband) that since he has sex with other women he can get infected. I told him that I had no objection in him having sex with other women provided he used condoms. But he simply refused and now his disease (HIV) has passed on to me.

\section{Shabana, 35-year-old woman/I}

Other reasons for inconsistent condom use included misconceptions that condoms are only used by sex workers or are required only for sex with an infected partner. Drugs were found to be an important influence on condom use. One woman/I reported that she could not remember to use condoms under the influence of drugs while another woman disclosed that she was too 'drugged' to even realise when sex happened.

Sexual violence was prevalent. Some women/NI reported coercion from their partners to have anal or oral sex. Women were reluctant to engage in such acts for fear of infection, perception that anal sex is abnormal and/or their belief that it is against their religion. There was no mention of condom use during these acts. As a 23-year-old participant narrated:

He (husband) asks me to let him do from behind (anal)...but when I refuse he starts sulking...I feel scared; I have never done it... Eunuchs do it this way, wives at home don't...he makes me suck (oral sex) also. Yesterday, he forced it in my mouth.

\section{Laxmi, 23-year-old woman/NI}

Some women also reported having sex with their regular partners during menstruation, although a few refused for the fear of infecting their partners with their menstrual blood.

\section{Paid sexual partnerships}

With limited literacy and employable skills, women found it difficult to have a stable job and hence some of them engaged in sex work. The economic needs varied from financing their own or partner's drug use or to be the economic caregiver while their male partners were either incarcerated or had abandoned them.

Women/NI who were younger in age and not into heavy drug use were more likely to report sex work. While many participants did it of their own volition others were led to it by their peers and a few were violently coerced by their male partners.

Salim (husband) and his family pushed me into sex work. They would beat me black and blue whenever I resisted. My mother-in-law once burnt my stomach with a cigarette.... My husband would often twist my hand and threaten to break it. These black patches 
that you see (showing her forehead) are because he used to hit me with bottles...

\section{Suman, 21-year-old woman/I}

I used to go out with other women to do drugs... they suggested that I can earn good money by doing wrong work (sex work), so I started going with them. We used to attract men, do it (sex) and get our money

$$
\text { Meena, 22-year-old woman/NI }
$$

Women also complained of frequent misbehaviour from their clients as they subjected them to sexual violence (such as coercion for unprotected sex) or declined to pay for their services. Women also reported instances where custodians of the law-the local policemen-solicited sexual favours to provide them impunity against sex work, which is illegal in India.

You will find both good and bad policemen... In lots of places they say do it (sex) with us then we will let you earn. We do it with them but not all of them use condoms.

$$
\text { Naseem, 29-year-old woman/NI }
$$

Unsafe sex within paid partnerships

Women faced considerable risk of STIs and unintended pregnancies since most reported infrequent condom use for reasons such as influence of drugs, offer of extra money, fear of violence, or low client volume. The skewed power dynamics in the client-sex worker relationship significantly influenced their negotiation for safe sex.

At times, I was really high to negotiate or I didn't have it (condom) and the client also didn't have money to buy it... Some men said they don't enjoy with it (condom)...men are like that only. When they give money ... They want us to do whatever they ask.

\section{Mala, 35-year-old woman/NI}

To minimise the ill-effects of inconsistent condom use, women reported using their own discretionary strategies to assess risk of getting infected. One participant reported refusing unprotected sex if the client injected drugs as he was more likely to be infected, while another refused sex if the clients had visible symptoms of infection.

Once a man came and asked me to switch off the lights while having sex... Then I saw that the bottom of his testicles was so fat, filthy and smelly. I felt so scared... I told him that you would give me 100 to 200 rupees (for sex) but I will get sick and my life will be spoiled. I then chased him away.

\section{Iram, 40-year-old woman/I}

A small number of participants expressed concern that condoms were not completely safe as they had experienced frequent tears. Traditional practices, such as urinating or washing their genitals immediately after unprotected sex, gave them a false sense of protection against possible adverse health outcomes.
NEGATIVE SRH-RELATED OUTCOMES COUPLED WITH LOW UPTAKE OF HEALTHCARE SERVICES

Symptoms suggestive of RTI/STI

Abnormal vaginal discharge, itching, dyspareunia and genital ulcers were frequently reported. Two of the commonly cited reasons for contracting infections were multiple sex partners of their regular partners and unprotected sex with clients. Women/NI who had these symptoms reported male partners with symptoms of genital itching, penile discharge or genital ulcers. Further, physical weakness, use of unhygienic toilets and not "washing-off' genitals after having sex were other reasons cited. However, in many cases, women could not explain the reasons for having such symptoms.

There was a mixed response to access to treatment for these symptoms. Many women did not perceive the need for seeking treatment for itching and vaginal discharge as they believed it was a common occurrence among women. Embarrassment in explaining symptoms, undergoing physical examination and cost of treatment further discouraged them from seeking medical help. Stigma also emerged as a significant barrier in seeking healthcare. One participant complained of being turned away without treatment for her genital ulcers since she was a drug user. Therefore, use of home remedies or self-treatment from local pharmacy stores for symptomatic treatment was commonly reported.

I often have a yellow coloured vaginal discharge. Friends told me to go to private hospital as no one in government hospital gives medicine properly...but I don't have money so from where will I get my tests and treatment done? I think it's because of weakness that I've this problem of discharge

\section{Farha, 34-year-old woman/NI}

\section{Conception: coerced or unfulfilled desire}

Among married and sexually active participants, somemore so the women/NI-expressed a desire to have children. While only one of them never had children, others who wanted to conceive were women who either had only one child or had lost their children. High mortality among children of drug users was commonly reported and was an important reason cited for their desire to have more. A few women also reported pressure from their male partners to bear children with them, despite having children from previous relationships.

I did not want to conceive but my husband insisted. We used to fight at times.... I argued that he had multiple wives and must be having kids from them, so why does he want them from me? ...He said that he only has a son and wants a daughter now.

\section{Shobha, 35-year-old woman/I}

On the other hand, some participants who wanted to conceive reported miscarriages; of these a few women/I experienced multiple miscarriages. The reasons for 
miscarriage included accidental falling after drug use, inappropriate medication due to non-disclosure of drug use, intimate partner violence and witchcraft.

I was using drugs at that time; it was raining and I slipped because of which I lost my pregnancy... I went to a female doctor near my house. She gave me medicines to clean out the womb.... I didn't tell her that I used drugs for the fear that she wouldn't give me medicines.

Kamla, 35-year-old woman/I

Most women blamed drug use for their miscarriages and difficulty in conception as they not only heard from their peers but they themselves believed that women who use drugs suffer menstrual irregularities and infertility.

We tried to conceive for a long time but it was just not happening...we lived in Jamuna Bazaar [a wellknown hotspot for drug users] and everyone there knew that women who use drugs have such problems.

Neeta, 28-year-old woman/I

Women who did visit a healthcare facility to seek treatment for their reproductive health issues/problems were disappointed. Women often received evasive and unsatisfactory explanations, ill-treatment and negative attitudes from healthcare providers because of their drug use and unkempt appearance. Challenges in navigating healthcare facilities were also cited.

I visited the government hospital since I was unable to conceive. The doctors just did the check-up and gave medicines but they did not tell me anything. I even went to a private hospital for 2-3 months, got my tests done but nothing happened...I gave it a year and then left it. Doctors don't treat us well; they don't do the check-up properly...they are always in a hurry...

Bina, 21-year-old woman/NI

Sometimes it (menstruation) doesn't happen for months together...I thought of getting a check-up done but since I use smack how will I or from where will I get treatment.

Shanti, 28-year-old woman/I

\section{Unmet family planning needs}

Some of the sexually active participants were keen to limit their family size. Reasons included having achieved the desired family size, financial constraints in raising more children and fear that their children will eventually use drugs. These women reported various modern and traditional methods to prevent pregnancy: condoms, contraceptive pills, injectable contraceptives, abstinence, sex during menstruation, and sterilisation.

After delivery of my second baby, I explained to him different ways of contraception, sterilisation, pills and condoms. He was against sterilisation as he thought I could die during the process and I was against pills as I tend to forget. So, finally we decided to use condoms.

$$
\text { Maya, 31-year-old woman/I }
$$

The most commonly used contraceptives were condoms and oral contraceptive pills (OCPs) which are easily available at the government healthcare facilities and local pharmacy stores. Despite their desire to limit family size and awareness about various contraceptives, participants reported none or infrequent and inconsistent use. Use of OCPs was reported as an 'unnecessary headache' as adherence due to unstable lifestyle and drug use was difficult. Weakness due to OCPs and fear of other possible ill-effects were also cited. Not many women knew about injectable contraceptives; among those who were aware, cost was reported to be a key barrier. Poor uptake of condoms in the context of different partnerships has been reported above.

Unplanned and unintended pregnancies at times resulted in termination of pregnancy, as one participant narrated:

When I got pregnant, I went and took medicines to abort it. I kept lying on the bed for 2-3 days till I bled...I told my mother-in-law, your son uses drugs so how will I raise this child? My husband also now feels that it was the right decision...he cannot earn, how would he feed or educate the child...

$$
\text { Chanda, 32-year-old woman/NI }
$$

\section{DISCUSSION}

To the best of our knowledge, this is the first study which attempts to provide contextual understanding of SRH (beyond HIV)-related behaviours and the needs of women who use drugs in Delhi, the capital city of India. Study findings provide key insights for women who use drugs through non-injecting routes (ingesting, inhaling, chasing, snorting, sniffing or smoking), hitherto a gap in our knowledge, and explores possible differences that may exist in comparison to women who inject drugs. In our study, women/I were found to be older, less likely to be sexually active, and engaged in sex work, and more likely to be divorced or separated than women/NI. Similar findings have been reported from a study with WUD in north-east India. ${ }^{23}$

Study findings indicate that drug use pushes women into a chaotic lifestyle which adversely impacts their personal relationships. This was similar to findings by Lal $e t a l^{24}$ who reported that women substance users have more problems in their family and social network and thus are more likely to separate or divorce than their male counterparts. ${ }^{24}$ Women in our study sought recluse from abusive relationships and built newer partnerships for their emotional fulfilment, to get social protection from a male partner and, to some extent, bring stability in their lives. 
Many study participants were sexually active with their regular partners. Inconsistent condom use was widely reported due to established gender power imbalance, fear of violence, and misconceptions embedded within the institution of marriage. Condoms were not used even when regular partners were known to have multiple sex partners. Sexual violence was prevalent as coercion for anal sex-which put women at greater risk of HIV transmission compared with penile-vaginal sex $(1.7 \%$ vs $0.8 \%$ )—was reported. ${ }^{25}$

Participants who engaged in sex work faced a twofold risk since both sex work and drug use are illegal in India. This often resulted in uneven power dynamics unfavourable to women as they consequently faced violence and health risks through unprotected sex. In such circumstances, women used their own discretion and negotiated condom use with clients who were more likely to be infected while they continued to remain at risk of being infected or impregnated otherwise. The high prevalence of IPV, as reported by our participants, illustrated its role in shaping sex behaviours as women were more likely to agree to unsafe sex for fear of violence. Chamberlain $e t$ $a l^{26}$ and Moore $e t a l^{27}$ have also illustrated the role of IPV in predicting poor reproductive health outcomes.

In India, harm-reduction services for people who use drugs are limited to prevention of HIV and other STIs, thus overlooking other reproductive health needs such as family planning. A study in the north- eastern part of the country identified reproductive health problems as one of the most commonly reported issues among WUD. ${ }^{15} \mathrm{We}$ found similar gaps of unaddressed reproductive health needs among our study participants. Among women who desired to conceive, multiple miscarriages and inability to conceive were reported, especially by women/I. A possible explanation is the well-established association between heavy drug use and poor reproductive outcomes such as spontaneous abortion, restricted fetal growth and incorrect maternal placentation. ${ }^{28}$ At the same time, many others reported unintended and unplanned pregnancies despite high levels of awareness about modern methods of contraception. Gender power imbalance, which affected women's involvement in decision-making for family planning, and the influence of the drugs themselves were important reasons reported for infrequent contraceptive use. Thus, our qualitative study, although with limited scope for generalisability, shows that the SRH needs of women who inject drugs and those who use drugs through non-injectable routes were largely similar. However, women/NI, being younger in the reproductive age span, were more sexually active (including sex work) and hence may have an increased risk of poor SRH-related outcomes.

The theory of reasoned action ${ }^{29}$ argues that individuals consider the consequences of their sexual behaviour before undertaking them. However, a reasoned action to ensure better health outcomes may not be possible for our study population, since their immediate needs could be financing the next drug dose or feeding her children or herself, in which case her action cannot be determined by 'potential but not immediate' consequences on health.

Our study illustrated a mixed response on low uptake of healthcare services. Women acknowledged the need for healthcare services but did not access them for reasons such as embarrassment in discussing intimate problems, stigma from healthcare providers, and high costs. Additionally, women did not seek medical help for problems which are perceived to be common among WUD or women in general, suggesting a lack of accurate information to correctly comprehend conditions which need medical attention. However, correct information could not always ensure safe behaviours as many involve dyadic decision-making with sexual partners. Further, WUD are stigmatised by society because they are viewed (and often view themselves) as having deviated from the traditional societal norms (such as multiple sex partners), thus stigma has a key influence on the health-related decisions of these women. Thus, SRH-related behaviours and the needs of this group are a complex interplay which demand a coordinated multidimensional approach to address issues at all levels-individual, family, community and institutional.

Based on our study findings, we suggest a two-pronged approach to holistically address the healthcare needs of WUD: first, women should be equipped with the correct information pertaining to their SRH to improve their selfrisk assessment skills and consequently identify their need for treatment and seek healthcare services. Second, healthcare providers should be trained to provide respectful and tailored services to address the specific needs of this group. This capacity building exercise should include community workers-ORWs and peer educators-to provide services such as counselling for family planning, identifying pregnant drug-using women and linking them to appropriate ante- and postnatal services and child care.

Further, there is an urgent need to set up community-based women-centric targeted interventions, which act as a 'one-stop-shop' for a comprehensive package of health services. These could be expanded models of existing DICs with a few hours per week dedicated for all WUD, including women/NI. This package should not only include reproductive health services through a visiting gynaecologist but also provide opioid substitution therapy, detoxification and rehabilitation services. Provision of mental health services can go a long way in making women more receptive and adherent to these services.

The study is not without its limitations. ORWs could recruit only those women who they knew used drugs or those who disclosed their drug use behaviour during the recruitment phase. Further, the qualitative study design and analysis plan was not designed to derive any prevalence estimates of the needs and behaviours identified as relevant by the study participants. 


\section{CONCLUSION}

Study findings indicate that SRH-related behaviours and the needs of WUD are a complex interplay of unstable and abusive relationships, stigma, influence of drugs, lack of correct information, and trained healthcare providers. Therefore, it is imperative to roll out community-based women-centric services with appropriate provisions for drug dependence treatment as well as reproductive health services. A survey with a representatively sampled group of WUD will strengthen the study's findings.

Contributors VS, AS, WT and IT conceived and designed the study. VS, LRS and IM recruited and interviewed participants, transcribed interviews and analysed the data. AS and SL provided critical conceptual inputs on the analysis and in drafting the manuscript. All authors agreed with the results and conclusions of the research and reviewed and approved the final manuscript.

Funding Support for this project was provided by ARISE - Enhancing HIV prevention for at-risk populations, through financial support provided by the Canadian Government through Foreign Affairs Trade and Development Canada, and via financial and technical support provided by PATH (CID.1450-02135-SUB), The ARISE project implements innovative HIV prevention initiatives for vulnerable communities, with a focus on determining cost-effectiveness through rigorous evaluations.

Competing interests None declared.

Ethics approval Institutional Review Board, Population Council and Research Ethics Committee, PATH.

Provenance and peer review Not commissioned; externally peer reviewed.

Data sharing statement The audio recordings and transcribed interviews are stored in a password protected system with the project team at the Population Council, India office. The privacy of the data is maintained since participants did not consent for data to be shared beyond the research team.

Open Access This is an Open Access article distributed in accordance with the Creative Commons Attribution Non Commercial (CC BY-NC 4.0) license, which permits others to distribute, remix, adapt, build upon this work non-commercially, and license their derivative works on different terms, provided the original work is properly cited and the use is non-commercial. See: http://creativecommons.org/ licenses/by-nc/4.0/

(c) Article author(s) (or their employer(s) unless otherwise stated in the text of the article) 2017. All rights reserved. No commercial use is permitted unless otherwise expressly granted.

\section{REFERENCES}

1. Roberts A, Mathers B, Degenhardt L. Women who inject drugs: a review of their risks, experiences and needs, 2010.

2. National AIDS Control Organization. Ministry of health and family welfare. Annual report 2012-13, 2013.

3. UNODC and UNAIDS. India country advocacy brief: injecting drug use and HIV.

4. Powis B, Griffiths P, Gossop M, et al. The differences between male and female drug users: community samples of heroin and cocaine users compared. Subst Use Misuse 1996;31:529-43.

5. UNODC and ICDDR. Rapid situation and response assessment among female drug users and female sex partners of male drug users in Bangladesh, 2010.
6. Paone D, Cooper H, Alperen J, et al. HIV risk behaviours of current sex workers attending syringe exchange: the experiences of women in five US cities. AIDS Care 1999;11:269-80.

7. Plant ML, Plant MA, Peck DF, et al. The sex industry, alcohol and illicit drugs: implications for the spread of HIV infection. Br J Addict 1989;84:53-9.

8. Strathdee SA, Philbin MM, Semple SJ, et al. Correlates of injection drug use among female sex workers in two Mexico-U.S. border cities. Drug Alcohol Depend 2008;92:132-40.

9. Murthy P. Female injecting drug users and female sex partners of men who inject drugs: assessing care needs and developing responsive services, 2012.

10. Panda S, Bijaya L, Sadhana Devi N, et al. Interface between drug use and sex work in Manipur. Natl Med J India 2001;14:209-11.

11. Ministry of Social Justice and Empowerment (Gol) and UNDCPROSA. Women and drug abuse: the problem in India, 2002.

12. Devine A, Bowen K, Dzuvichu B, et al. Pathways to sex-work in Nagaland, India: implications for HIV prevention and community mobilisation. AIDS Care 2010;22:228-37.

13. Lucas GM, Solomon SS, Srikrishnan AK, et al. High HIV burden among people who inject drugs in 15 Indian cities. AIDS 2015;29:1.

14. Des Jarlais DC, Arasteh K, McKnight C, et al. HSV-2 co-infection as a driver of HIV transmission among heterosexual non-injecting drug users in New York City. PLoS One 2014;9:e87993.

15. Kermode $\mathrm{M}$, Songput $\mathrm{CH}$, Sono $\mathrm{CZ}$, et al. Meeting the needs of women who use drugs and alcohol in North-east India - a challenge for HIV prevention services. BMC Public Health 2012;12:825.

16. Kermode $\mathrm{M}$, Sono $\mathrm{CZ}$, Songput $\mathrm{CH}$, et al. Falling through the cracks: a qualitative study of HIV risks among women who use drugs and alcohol in Northeast India. BMC Int Health Hum Rights 2013;13:9

17. National AIDS Control Organization, Ministry of Health and Family Welfare. Mid-Term Appraisal of National AIDS Control Programme Phase IV. 2016 http://www.naco.gov.in/sites/default/files/Report\% 20of\%20the\%20MTA\%20of\%20NACP\%20IV\%20-\%20August\% 202016.pdf

18. Sarna A, Tun W, Sharma V, et al. High uptake of HIV testing in a cohort of male injection drug users in Delhi, India: prevalence and correlates of HIV infection. AIDS Behav 2013;17:2479-89.

19. Berger PL, Luckmann T. The Social Construction of Reality A Treatise in the Sociology of Knowledge: Penguin Group, 1966.

20. Tun W, Sebastian MP, Sharma V, et al. Strategies for recruiting injection drug users for HIV prevention services in Delhi, India. Harm Reduct J 2013;10:16.

21. Braun V, Clarke V. Using thematic analysis in psychology. Qual Res Psychol 2006;3:77-101.

22. Pope C, Ziebland S, Mays N. Qualitative research in health care. Analysing qualitative data. BMJ 2000;320:114-6.

23. Kumar S, Oinam A, Debashis M, et al. Women who use drugs in Northeast India, 2015

24. Lal R, Deb KS, Kedia S. Substance use in women: current status and future directions. Indian J Psychiatry 2015;57:275.

25. Boily MC, Baggaley RF, Wang L, et al. Heterosexual risk of HIV-1 infection per sexual act: systematic review and meta-analysis of observational studies. Lancet Infect Dis 2009;9:118-29.

26. Chamberlain L, Levenson R. Addressing intimate partner violence, reproductive and sexual coercion: a guide for obstetric, gynecology and reproductive health care setting: American College of Obstetricians and Gynecologists, 2012.

27. Moore AM, Frohwirth L, Miller E. Male reproductive control of women who have experienced intimate partner violence in the United States. Soc Sci Med 2010;70:1737-44

28. Gyarmathy VA, Giraudon I, Hedrich D, et al. Drug use and pregnancy - challenges for public health. Euro Surveill 2009;14:33-6.

29. Fishbein M, Aizen I. Belief, Attitude, Intention, and Behavior: An Introduction to Theory and Research: Addison-Wesley, 1975. 